706

\title{
メルトドラッグ法を応用した実用 $\mathrm{Al}$ 合金の アルミハニカムサンドイッチパネルの微細組織と接合特性の調査
}

\author{
狩野 達広 ${ }^{* 1}$, 小山 拓馬 ${ }^{* 2}$, 遠藤 正樹 ${ }^{* 3}$, 原田 英人 ${ }^{* 4}$, 西田 進一 ${ }^{* 5}$, 渡利 久規6 \\ Microstructure and Bonding Property of Aluminum Honeycomb Sandwich Panel \\ By Melt Drag Process
}

\author{
Tatsuhiro KANO*1, Takuma KOYAMA, Masaki ENDO, Hideto HARADA \\ Shinichi NISHIDA, Hisaki WATARI \\ ${ }^{* 1}$ Department of Production Science and Technology, Graduate School of Engineering, Gunma University \\ 29-1, Hontyo, Ota, Gunma, 373-0057, Japan
}

\begin{abstract}
Aluminum honeycomb has superior properties which is light weight, high rigidity, energy absorption more than bulk aluminum. In present the aluminum honeycomb sandwich panel (AHS) is used for structural materials such as aerospace panel and house materials. The AHS is generally made from honeycomb core and aluminum alloy panel. These honeycomb core and panel are bonded with the bond. The bond is often not good for heat resistance or recyclability in some situations. The aim of this study is to clarify microstructure and bonding property to manufacture AHS by melt drag process without the bond.
\end{abstract}

Key Words : Aluminum alloy, Aluminum honey comb sandwhith panel, Melt drag prosess, Bonding

\section{1. 緒言}

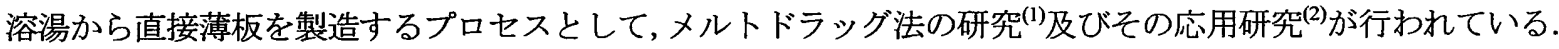
一方, アルミニウムハニカムパネルは, 軽量, 高剛性, エネルギー吸収性, 高断熱性等の, 優れた特性を有して おり，航空機を始めとした軽量化が求められる部材への工業的応用が期待されている. 従来のサンドイッチパネ ルは一般的に接着剤を使用して接着しているため, 工程数が多く, 耐熱性や施工性が低下するといった問題があ る. 仮に接着剤を使用しないハニカムサンドイッチパネルが作製できれば，省工程化や適用部材の拡大だけでな く, 上記の特性が向上するものと考えられる. 著者らは, メルトドラッグ法にて作製する薄板の自由凝固面に存 在する半凝固層を接合に利用することで, 接着剤を使用しないパネル材に実用 $\mathrm{Al}$ 合金を適用したアルミニウム八 ニカムサンドイッチパネルの作製に成功している(3). 今回，作製したサンドイッチパネルの接合部界面の微細組 織と接合特性について調查したので報告する.

\section{2. 実験装置と実験条件}

本研究で使用した実験装置を図 1 に示す。メルトドラッグ法にはクローズドトップタイプと，オープントップ タイプがある. 本プロセスでは薄板の自由凝固面上の半凝固部分を利用するため, 凝固距離を短くし凝固時間を 短くするためにクローズドトップタイプを採用した. 使用した実験装置は，一対の凝固ロールとノズル（溶湯が

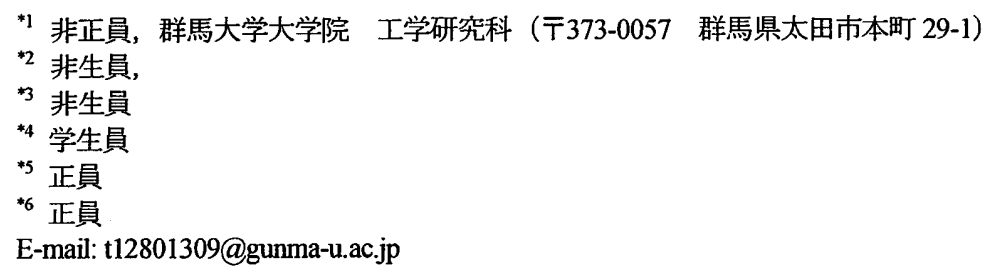


溜まる部品）から成る．使用した凝固ロールの材質は A5052 であり，ロールサイズは，直径 $200 \mathrm{~mm}$ ，幅 $50 \mathrm{~mm}$ である. 左右に配置した凝固ロールにて薄板を作製し, 自由凝固面の凝固が完了する前に, 装置上部からロール 間隙にハニカム材を挿入する．挿入されたハニカム材は，薄板の自由凝固面に存在する半凝固層にハニカムの䈃 の一部を食い込ませて接合し，同時に装置下方に設置した水冷装置にて凝固を完了させ，アルミハニカムサンド イッチパネルをサンプルとして得た. 実験に使用したアルミハニカム材の概略図を図 2 に, 組成を表 1 に示す. 八ニカム材の寸法は図 2 に示すようにW 方向が $100 \mathrm{~mm}$ ，L 方向が $20 \mathrm{~mm} ， \mathrm{~T}$ 方向が $20 \mathrm{~mm}$ であった. 八ニカム材 の方向は, パネル材と接触する面をハニカム材の開放方向とした. 実験により得られた各種実用 $\mathrm{Al}$ 合金をパネル 材に適用したサンドイッチパネルの作製可能条件は, A5052 の場合, ロール周速 $30 \mathrm{~m} / \mathrm{min}$, 溶湯温度 $650^{\circ} \mathrm{C}$, ， ズル出ロギャップ $4 \mathrm{~mm}$, 薄板表面温度 $643^{\circ} \mathrm{C}, \mathrm{A} 6063$ の場合, ロール周速 $30 \mathrm{~m} / \mathrm{min}$, 溶湯温度 $655^{\circ} \mathrm{C}$, ノズル出 ロギャップ $3 \mathrm{~mm}$, 薄板表面温度 $652^{\circ} \mathrm{C}$ であった. A7075 の場合, ロール周速 $30 \mathrm{~m} / \mathrm{min}$, 溶湯温度 $655^{\circ} \mathrm{C}$, ノズル 出口ギャップ $3 \mathrm{~mm}$, 薄板表面温度 $630^{\circ} \mathrm{C}$ で作製可能であった. パネル材に適用した $\mathrm{Al}$ 合金の組成を表 2 に示す. 各種合金とも八二カム材とパネル材の接触時の薄板表面温度は液相線温度-10 以内であり, 薄板表面が半凝固状 態であった. 上記の実験条件で作製したサンドイッチパネルの微細組織と接合特性の調査として，フラットワイ ズ剥離試験，およびEPMA による観察，熱処理による接合状態の向上を試みた.

\section{3. 実験結果および考察}

図 3 に作製したサンドイッチパネルの断面写真を示す.作製したサンドイッチパネルはハニカム材が座屈せず， 箔がパネル材に対しほぼ垂直かつ変形せずに刺さっていることが確認された。作製し得られたサンドイッチパネ ルの接合特性の調查として剥離試験を行った. 図 4 に剥離試験の結果として, A5052, A6063, A7075 の各サンド イッチパネルのフラットワイズ剥離試験による応力変位曲線を示す. フラットワイズ剥離試験は, サンドイッチ パネルのパネル面を万能試験機にて試験速度 $1 \mathrm{~mm} / \mathrm{min}$ で剥離した. サンドイッチパネルの剥離挙動として, 引 張開始直後に引張応力が増加し, ピーク応力（最大引張応力）を示した後, 接合部の剥離が始まり応力は低下寸 る. サンドイッチパネルの最大引張応力は, A5052 が約 0.053MPa, A6063 が約 0.015MPa, A7075 が約 0.644MPa を示した. 図 5, (a), (b), (c)に最大引張応力を示したサンドイッチパネル (A7075) の EPMAによる BSE 像, マ ッピング分析結果 (亜鉛), 線分析結果を示す. 接合部のハニカムの箔の先端において, 八ニカム材とパネル材の 境界が不明慮になっていることから溶融接合していることが確認された．また，作製したサンドイッチパネルに 熱処理を施し, 接合状態の向上を試みた. 熱処理条件は, 電気炬内の空気雾囲気中で $500^{\circ} \mathrm{C}, 7$ 時間保持し溶体 化処理した後, 空冷した. 図 6, (a), (b), (c)に熱処理を施したサンドイッチパネル (A7075) の EPMAによる BSE 像, マッピング分析結果 (亜鉛), 線分析結果を示す. マッピング分析の結果から熱処理によりハニカム材とパネ ル材の界面が不明慮になっていることが確認された。 ハニカム材における亜鉛の含有量は 0.01(mass\%)であり， パネル材に使用した A7075 は亜鉛の含有量が 5.1〜 6.1(mass\%)である. 図 5, 図 6 の線分析の結果の比較によ り，熱処理を施したサンドイッチパネルは接合部の垂直方向において亜鉛が拡散していることが確認でき，接合 は機械的接合と溶融接合の複合的な接合であると考えられ, そのため, A7075 サンドイッチパネルは他と比較し， 高い剥離強度を示したと推測される．また，熱処理によるサンドイッチパネルの変形は無かった．以上の実験に より,メルトドラッグ法を応用し作製した寒用 $\mathrm{Al}$ 合金のアルミハニカムサンドイッチパネルは, 熱処理により接 合状態を向上させることが可能であることが示された.

\section{文献}

（1）西田進一ほか：軽金属, 57-10(2007),439-443.

(2) 木村哲ほか : 塑性加工学会秋期大会講論, 2010 (2010), 135-136.

（3）狩野達広ほか：軽金属学会春季大会概要，2012，333-334. 


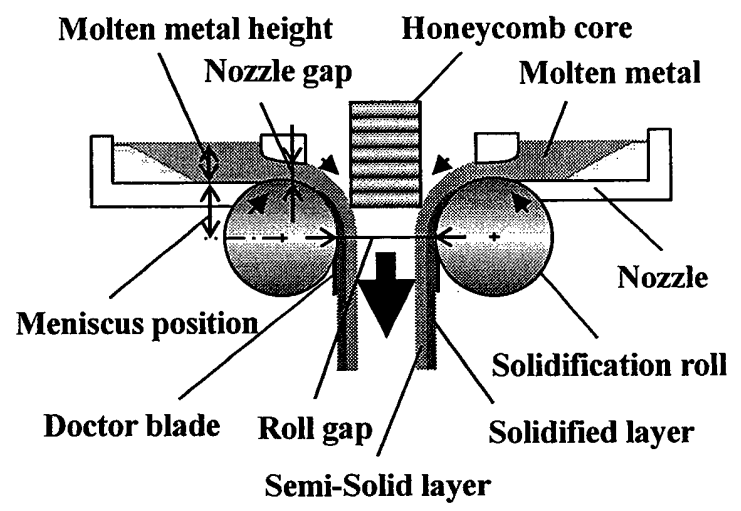

Fig.1 Schematic illustration of experimental device

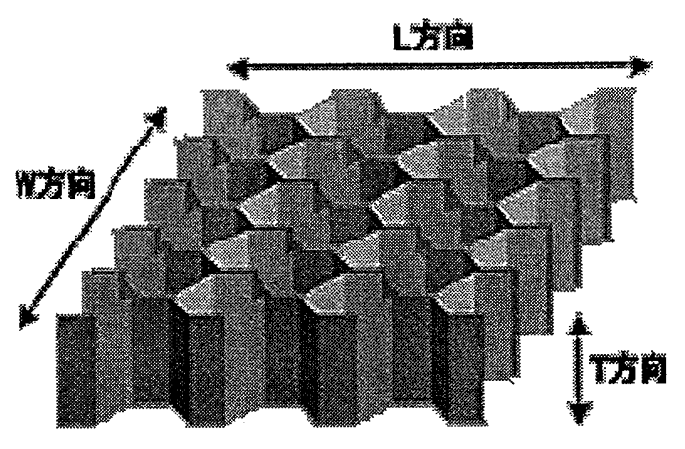

Fig.2 Honeycomb core

Table 1 Composition of aluminum honeycomb (mass\%)

\begin{tabular}{|c|c|}
\hline $\mathrm{Si}$ & Less of equal 0.25 \\
\hline $\mathrm{Fe}$ & Less of equal 0.40 \\
\hline $\mathrm{Cu}$ & Less of equal 0.10 \\
\hline $\mathrm{Mn}$ & Less of equal 0.10 \\
\hline $\mathrm{Mg}$ & $2.20 \sim 2.80$ \\
\hline $\mathrm{Cr}$ & $0.15 \sim 0.35$ \\
\hline $\mathrm{Zn}$ & Less of equal 0.10 \\
\hline $\mathrm{Al}$ & Bal. \\
\hline
\end{tabular}

Table 2 Composition of aluminum (mass\%)

\begin{tabular}{|c|c|c|c|}
\hline Aluminum alloy & $\mathrm{A} 5052$ & $\mathrm{~A} 6063$ & $\mathrm{~A} 7075$ \\
\hline $\mathrm{Si}$ & 0.25 & 0.6 & 0.4 \\
\hline $\mathrm{Fe}$ & 0.4 & 0.35 & 0.5 \\
\hline $\mathrm{Cu}$ & 0.1 & 0.1 & $1.2 \sim 2.0$ \\
\hline $\mathrm{Mn}$ & 0.1 & 0.1 & 0.3 \\
\hline $\mathrm{Mg}$ & $2.2 \sim 2.8$ & $0.45 \sim 0.9$ & $2.1 \sim 2.9$ \\
\hline $\mathrm{Cr}$ & $0.15 \sim 0.35$ & 0.1 & $0.18 \sim 0.28$ \\
\hline $\mathrm{Zn}$ & 0.1 & 0.1 & $5.1 \sim 6.1$ \\
\hline $\mathrm{Al}$ & Bal. & Bal. & Bal. \\
\hline
\end{tabular}

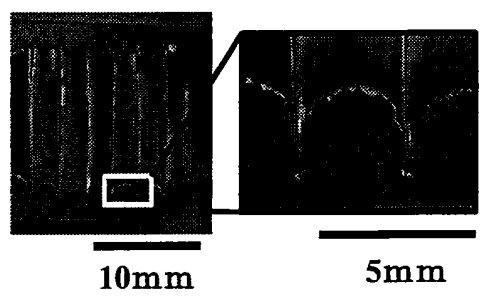

(a) Sandwich panel (A5052)

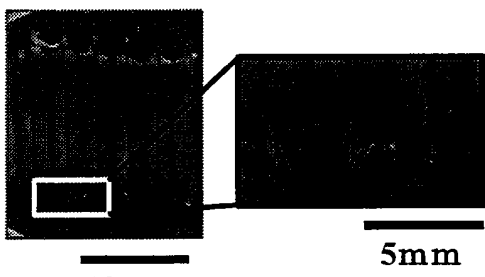

$10 \mathrm{~mm}$

(b) Sandwich panel (A6063)

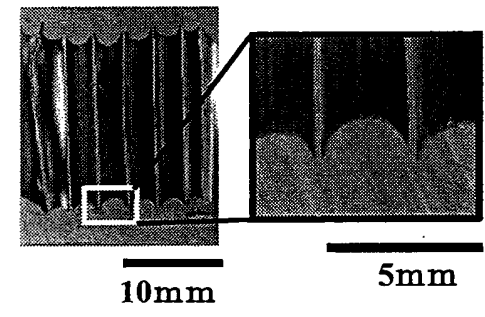

(c) Sandwich panel (A7075)

Fig.3 Cross section photograph of Aluminum honeycomb sandwich panel 


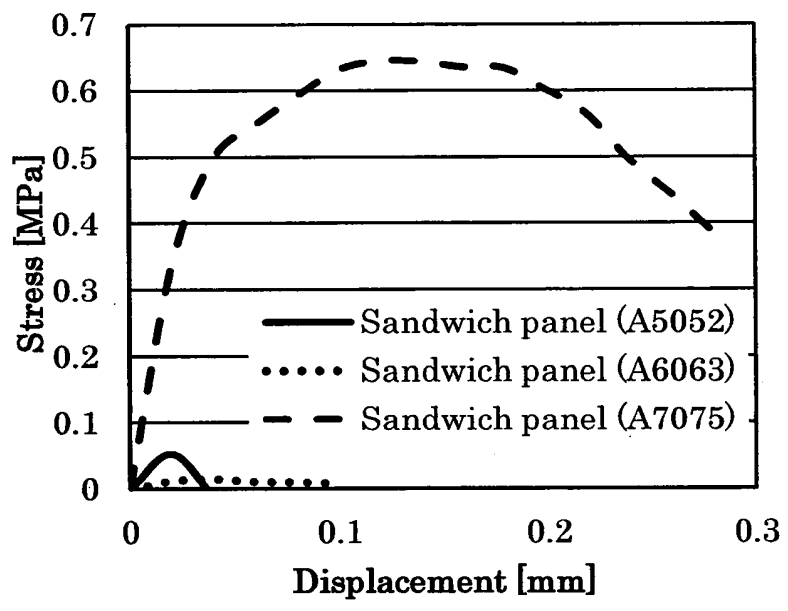

Fig.4 Stress-displacement diagram

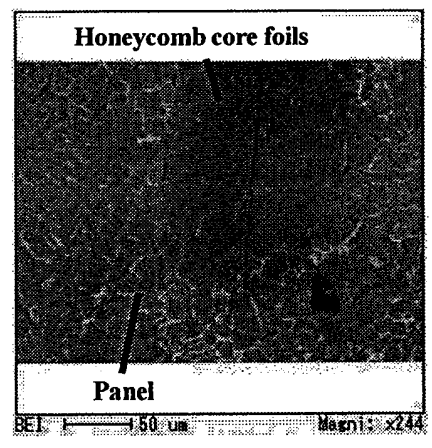

(a) BSE image

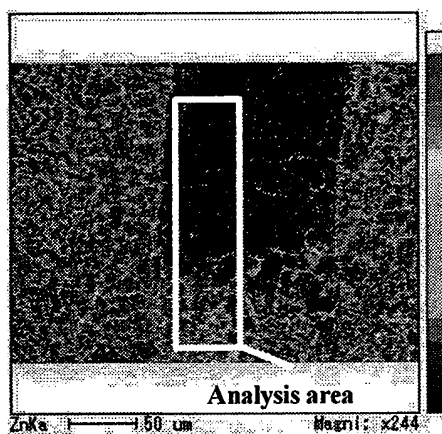

(b) Elemental mapping (Zinc)

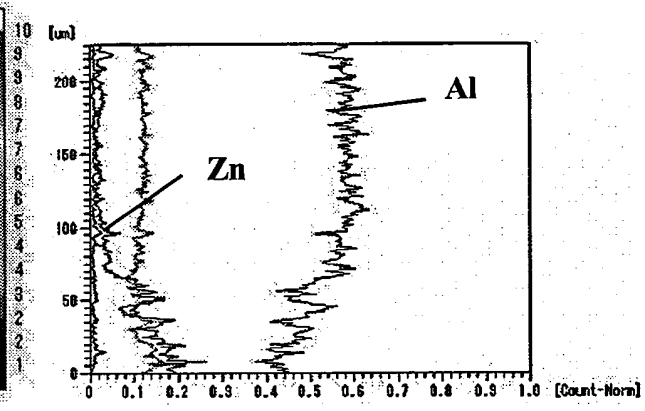

(c) Line analysis

Fig.5 Analysis results of A7075 AHS by Electron Probe Analyser (EPMA)

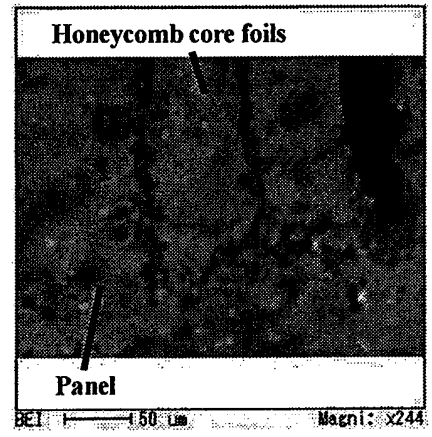

(b) BSE image

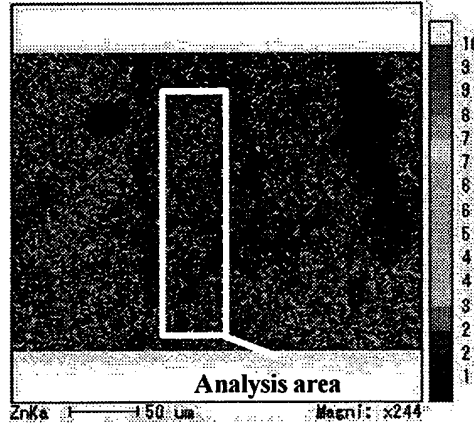

(b) Elemental mapping (Zinc)

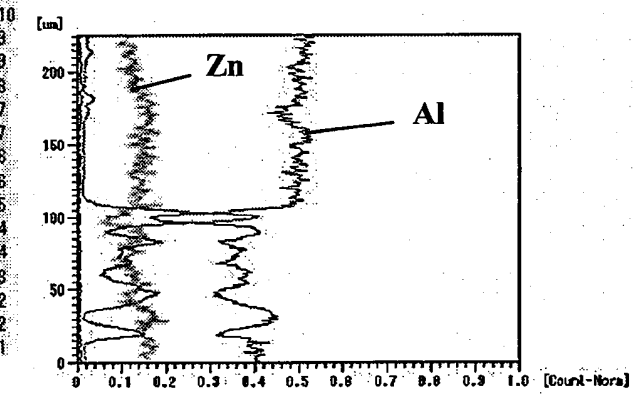

(c) Line analysis

Fig.6 Analysis results of A7075 AHS (heat treatment) by Electron Probe Micro Analyser (EPMA) 